This item was submitted to Loughborough's Research Repository by the author.

Items in Figshare are protected by copyright, with all rights reserved, unless otherwise indicated.

\title{
Stakeholders' response to the private sector participation of water supply utility in Karachi, Pakistan
}

PLEASE CITE THE PUBLISHED VERSION

PUBLISHER

(C) IWA Publishing

LICENCE

CC BY-NC-ND 4.0

REPOSITORY RECORD

Ahmed, Noman, and M. Sohail. 2019. "Stakeholders' Response to the Private Sector Participation of Water Supply Utility in Karachi, Pakistan”. figshare. https://hdl.handle.net/2134/3876. 
This item was submitted to Loughborough's Institutional Repository (https://dspace.lboro.ac.uk/) by the author and is made available under the following Creative Commons Licence conditions.

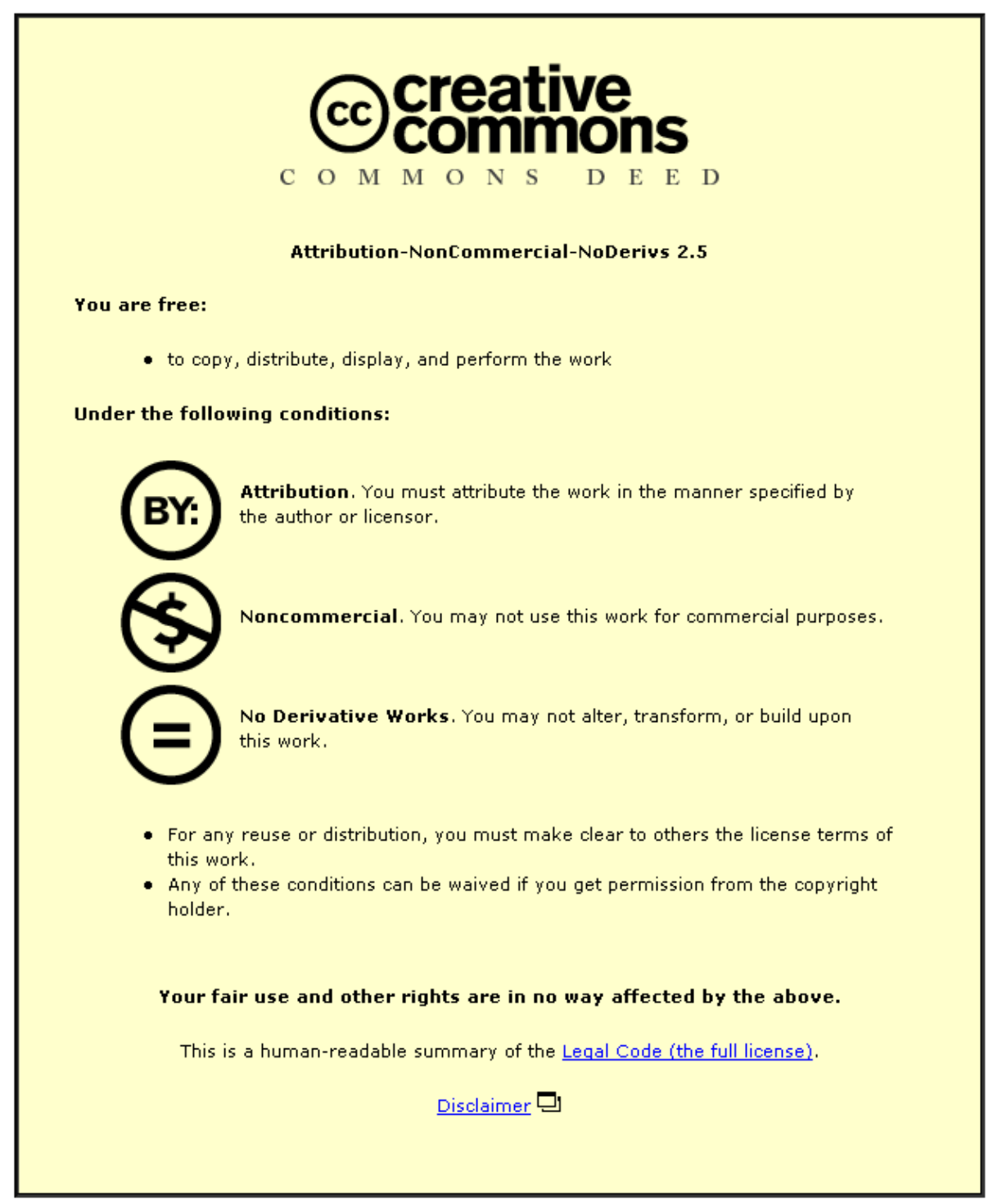

For the full text of this licence, please go to: http://creativecommons.org/licenses/by-nc-nd/2.5/ 
N. Ahmed and M. Sohail / Water Policy 6 (2003) 229-247

Stakeholders' response to the private sector participation of water supply utility in

\author{
Karachi, Pakistan \\ N. Ahmed* and M. Sohail ${ }^{* *}$ \\ *Department of Architecture and Planning, NED University of Engineering and Technology, \\ University Road, Karachi-75270, Pakistan. \\ **Corresponding author. Water Engineering and Development Centre, Institute of Development \\ Engineering, Loughborough University, Leicestershire LE 11 3TU, UK. Tel: +0044-1509- \\ 222890,E-mail: M.Sohail@lboro.ac.uk
}

Received 12 January 2003; accepted in revised form 29 August 2003

\begin{abstract}
Changes are proposed to improve urban water supply systems around the globe. Improvement in service delivery mechanisms, institutional efficiency, financial viability and acceptance by users are the key criteria for initiating and sustaining a change. To improve the situation of water supply in Karachi, Pakistan, advised by the World Bank, a private sector participation (PSP) strategy was formed during the 1990s. The strategy aimed to promote a gradual increase of PSP in water and sanitation services. The proposed project faced strong resistance from stakeholders, mainly civil society, leading to its suspension. Efforts are being made to revive the PSP and to make it acceptable to the stakeholders concerned. The paper documents and analyses the stakeholders' response to the anticipated PSP process and the possible social and economic impacts. The study makes a contribution in the areas of participation and consensus building in the context of PSP. Willingness to negotiate continuously
\end{abstract}


and even consideration of possible alternatives based on the changing situations are the key to any way forward for sustainable improvements.

Keywords: Privatisation, Stakeholders response, donors perspective.

\section{Privatisation of water supply in Karachi, Pakistan}

\subsection{Background}

Many private sector participation (PSP) strategies around the world face the issues described in paper. PSPs are proposed and attract huge support and opposition depending on one's viewpoint. In many cases the procurement process is delayed because of lack of agreement among the stakeholders. Studies like these that analyse and document the process leading to suspension of PSP processing are crucial to understanding the ways forward.

Traditionally, public sector institutions provided urban water supply services in cities around the world, through a variety of delivery procedures. Arrangements usually comprised direct provision through municipalities or their constituent departments, direct provision through special purpose authorities, provision through corporate bodies under the direct control of the public sector and provision through autonomous or semi-autonomous organisations. The control of these arrangements varied depending on the social, political and economic context. As the service networks expanded, institutional arrangements also had to be made compatible with the emerging levels of demand ${ }^{1}$.

Studies of urban areas in the developing world have shown that the water supply and waste water disposal arrangements fall short of rising demand and the increasing expectations of consumers. There are many reasons why this situation arises. Low tariff levels, poor revenue recovery, political interference, obsolete technologies and overstaffing are some common

\footnotetext{
${ }^{1}$ See, for example, Rivera (1996).
} 


\section{N. Ahmed and M. Sohail / Water Policy 6 (2003) 229-247}

ailments. Despite the fact that the majority of these cities have loan and technical assistance arrangements with donor agencies, the situation has not improved. To address this, governments have tried various options. One of the possibilities is to turn to the private sector and arrange contractual agreements.

There are numerous reasons for adopting this approach. In the recent past, water has come to be considered as an economic good owing to expanding demand and the nature of the economic input that is required to generate and distribute it. In the view of governments, particularly those in developing countries, water supply should be a function of enterprise rather than public welfare. As a result of the different nature of their links with the system, the interests of different sets of stakeholders are often in conflict with one another. For example, where the developmental and managerial functions of providing water are largely carried out with the support of donor agencies, it is obviously in the interests of those donors to maintain the smooth and methodical repayment of loans. Urban management authorities, on the other hand, try to utilise the loans to expand service networks and to consolidate management. Similarly, political leaders wish to please voters, while consumers wish to obtain the best services at the least cost. Petty water vendors, meanwhile, tend to create conditions that increase sales of their water and may even do this at the cost of criminally disrupting the routine water supply system ${ }^{2}$. Such complex intentions often give rise to situations where the systems of supply breakdown and the service delivery network does not deliver the desired service level. In such situations, alternate arrangements have to be sought in order to create an efficient water supply system that functions to the satisfaction of the maximum number of stakeholders. Introduction of private sector participation (PSP) is one of these alternative arrangements.

\footnotetext{
${ }^{2}$ See, for example, Water and Sanitation Programme (WSP) (1998).
} 
One of the major concerns when introducing privatisation is the probable impact that it may have on consumers, mainly the urban poor. However, appropriately designed solutions usually prove to be useful and effective. In Santiago, Chile, for example, the government devised a targeted support package for the urban poor. This helped those on low incomes become revenue-generating customers of water similar to upper- and middle-income groups. To make this step possible, a water stamp system was devised where the government provided a subsidy to the water bills of low-income groups. The system has worked fairly well (Briscoe, 1997). In Conakry, Guinea, water utility performance was declining, so the government leased water sector assets to a private operator who was then paid a fee that reflected the full cost of providing water services. Initially, the government charged water customers only a quarter of this fee while the remaining amount was covered through a World Bank loan. Water users were informed about the whole package and were briefed about the price escalation that would take place in proportion to the service improvement. The package has worked fairly well (Rivera, 1996; Briscoe, 1998). Recently, private sector participation has been introduced in many cities in many countries. Adelaide (Australia), Buenos Aires (Argentina), Gdansk (Poland), Jakarta (Indonesia), Johor (Malaysia), Macao, Manila (Philippines), Northumbrian Water (in the United Kingdom) and Santiago (Chile) are some examples. These cities have entered into an entirely different set of arrangements for PSP. Such interventions have met with mixed results. While the World Bank normally terms privatisation as a means of reform, other stakeholders take a different view.

Privatisation was introduced in Pakistan mainly through the advice of donor agencies like the World Bank. The Karachi Water and Sewerage Board (KWSB) ${ }^{3}$ was taken as an initial case.

\footnotetext{
${ }^{3}$ As part of the ongoing local government reforms, KWSB was merged into the recently formed City District Government of Karachi during February 2003. It is officially called the Water and Sanitation Department (WSD). However its internal organisational structure, operations and billing/revenue generating prerogatives have remained unchanged.
} 


\section{N. Ahmed and M. Sohail / Water Policy 6 (2003) 229-247}

Unlike many urban centres in Pakistan, which are either located along a body of fresh water or depend on groundwater sources, Karachi receives water from distant sources. An extensive generation, filtration, pumping/boosting and piping system is an integral part of the water supply service in Karachi (see Table 1).

\subsection{Strategy for PSP in KWSB}

According to the feasibility study (Paribas \& Halcrow, 1998), KWSB faced two major problems; insufficient control of the network that resulted in inequitable distribution and sizable water losses, and unsatisfied retail consumers who were reluctant to pay the bills. The PSP in KWSB was based on premises that addressed these vital issues. It was envisaged that tariff increase must correspond to tangible improvements in levels of service. Water loss reduction was to be dealt as a priority. Budgetary subsidies to KWSB, which were continually provided by the Government of Pakistan (GoS) were not sustainable as the GoS had to concur its own budget constraints. Private sector, more precisely international water companies, possess the full range of technical and financial capacities to deal with the situation. The whole investment in this specific context could be to the extent of US\$ 4 billion or more to generate efficiency that could allow for phased increase in tariffs. Concession shall however remain an essential prerequisite at least during the initial phase of the project implementation.

The feasibility study outlined several prerequisites for the success of PSP. The consultants emphasised that investment in the programme must be service driven. From the various technical and financial studies, they had come to the view that a substantial improvement in service level could be achieved with modest investment, that is, around US\$ 100 million. A stable and predicable environment with an appropriately derived legal and institutional framework was deemed to be a necessary requirement for PSP. To make the whole enterprise 


\section{N. Ahmed and M. Sohail / Water Policy 6 (2003) 229-247}

attractive for the potential investors/private operators, it was suggested that a local financial institution might be approached to provide grace period financing during the initial years of PSP implementation. In the same respect, GoS was required to commit the increase in tariffs up to $20 \%$ per annum for at least the initial five years, to approach the GoP, the World Bank or Asian Development Bank (ADB) for risk guarantees (such as World Bank’s partial risk guarantee) and to make the appropriate relaxation in its own debt service timetable.

Following the advice of the World Bank, the Provincial Government of Sindh (GoS) prepared a private sector participation strategy in $1994^{4}$. The KWSB was advised of this decision in 1995. The key aspects of the strategy were transparency in the process ${ }^{5}$, obtaining the best expertise on the subject and keeping a close liaison with the World Bank. Drawing on their worldwide experience, the World Bank suggested a shortlist of eight leading international organisations to the GoS for consideration. These organisations possessed vast experience in water sector privatisation. The officials of the KWSB and the GoS attended deliberations on the subject in Paris during 1995 to obtain an insight from the various international experts (Banque Paribas, 1997).

Terms of reference were prepared for the consultants to assist in the process of PSP. The eight firms on the shortlist were invited to submit detailed technical and financial proposals. The terms of reference required the consultants to develop a PSP strategy for their preferred approach to Karachi's water supply and sewerage sector. Each strategy had to:

- $\quad$ involve the private sector in renewal, improvement, expansion, operations and maintenance;

\footnotetext{
${ }^{4}$ The participants in framing the basic details of PSP, including its Terms of Reference, were the Chief Minister of Sindh, Senior Minister of Sindh, Additional Chief Secretary to GoS and Managing Director of KWSB (Ahmed, 1998). As may be observed in the later discussion, more emphasis remained on financial aspects and less on service improvement affairs.

${ }^{5}$ See for example Whittington (2003).
} 
- $\quad$ conduct a detailed technical and financial feasibility study of the scenarios considered;

- $\quad$ assess the possible impacts of the PSP approach on key criteria;

- $\quad$ present a finance strategy for mobilising the investments to the GoS;

- $\quad$ prepare prequalification and bidding documents; and

- $\quad$ assist the GoS in the bidding process and draft the final contract document (Banque Paribas, 1997).

After clearance of the terms of reference, the eight organisations were invited to submit detailed technical and financial proposals. The proposals were evaluated by the steering committee with specialist advice provided by the World Bank, and were subsequently presented to the GoS for clearance.

As the executing agency, KWSB coordinated the PSP consultancy project that was carried out. The consultant's report on Phase I was submitted and approved with certain modifications. The agreed approach was structured into three phases (see Table 2). The first phase covered the development of the most appropriate PSP strategy. This phase is now completed. The second phase covered the preparatory work for the PSP. This phase was also completed and a detailed feasibility report submitted to the GoS. The third phase, implementation of the agreed programme, has been partly started. Some bidding documents were received from the short-listed contractors. However, owing to a Sindh High Court order, the process of private sector participation was temporarily halted in $1996^{6}$.

At present, efforts are being made to convert the KWSB into a water and sewerage regulatory authority while all executive tasks are being given to private entrepreneurs with a

\footnotetext{
${ }^{6}$ Some stakeholders, including the labour union and an ex-Managing Director of the KWSB, filed a writ petition in the Provincial High Court. In a hearing, the Sindh High Court has maintained the status quo on PSP (see Daily Dawn, Karachi 21 May 2003).
} 
suitable background. In other words, the current approach of the government aims to limit the functions of the KWSB to a body prescribing rules, regulations and procedures for the provision of water and sanitation services. The actual task of providing these services will eventually pass onto private operators who will have the freedom to frame rules of business after obtaining approval from the regulatory body.

\subsection{Advocacy and support for PSP by the government}

In order to publicise and develop a broad-based consensus on the need for the implementation of PSP in the KWSB, an intensive media campaign was carried out. This included meetings with concerned citizens via debates, seminars, workshops and questionanswer sessions on the PSP and involved a cross-section of people and organisations. Ministers, even those belonging to different regimes, affirmed their resolve to apply PSP as a top priority. A series of articles and letters to the editors in leading newspapers were also published. In addition, press notes were issued, journalists briefed and extensive dialogue held with non-government organisations (NGOs) and trade unions. Brochures were also printed and widely circulated and televised debates were held, all designed to reach as wide a spectrum of the citizens of Karachi as possible. Individual citizens, along with business and advocacy groups, participated in a wideranging debate on the subject (KWSB, 1998).

As a result of this well-defined media campaign, both the print and electronic media gave good coverage to various developments, covering almost all aspects of PSP in the KWSB.

During the public awareness campaign, efforts were made to ensure that accurate and impartial information was made available about the on-going process with regard to PSP strategies as proposed by the consultants and approved by the GoS.

\section{Stakeholders' response}


To obtain feedback on the issues relating to the private sector participation, a response was sought from the various stakeholders involved. This feedback was acquired via a preprepared set of questions discussed in an interview format with the research team. Below is a summary of the responses received from various categories of stakeholders. The same is also outlined in Table 3.

\subsection{The government's response}

A great deal of criticism was cited in the press, professional organisations and civil society groups against the concept, procedure and approach of PSP in the KWSB. In order to obtain an objective viewpoint, the GoS appointed an independent committee to look into the matter. This committee, which comprised two senior civil servants and two independent economists, was requested by the GoS:

- $\quad$ to look at the process of PSP in the KWSB from a financial, an administrative and a social angle;

- $\quad$ to examine the financial benefits, if any, to the GoS;

- $\quad$ to examine the commitments that were to be made by the GoP and the GoS;

- $\quad$ to review the affordability of the proposed rates, especially by the low-income groups, to pay water charges; and

- $\quad$ to review the mechanisms for payment of the foreign, as well as local/loans.

The independent committee, which was a panel of bureaucrats and working professionals, conducted several independent hearings with the concerned stakeholders to obtain directly their viewpoint. Though appointed by GoS, its conduct was fairly independent. After deliberations and contact with the donor agencies concerned, government departments, KWSB 
staff, NGOs/community-based organisations (CBOs) and concerned individuals, the committee gave its response.

The equity to be provided by the successful bidder was US\$50 million, one sixth of the total transaction. The remaining US\$250 million were to be borne by the governments of Pakistan and Sindh and World Bank’s Partial Risk Guarantee (PRG). In addition, the GoS agreed to increase tariffs in the pre-PSP period by $30 \%$ per year for five years, plus an increase of $20 \%$ in real terms for another five years. Besides, the GoS had agreed to provide suitable guarantees against the main categories of risk including political, revenue-related, collection, inflation, currency/transaction and force majeure. In the light of the feasibility, a risk mitigation package was finalised that included a GoP letter covering the commitments of GoS in the PSP-concession contract; US\$40 million from the World Bank-PRG, also backed by GoP counter guarantee and a US\$50 million available on an escrow account to be disbursed in favour of the project lenders upon the occurrence of predefined events. All this was aimed at helping the successful bidder without them having to give any firm guarantees. Despite a most favourable contractual deal, representatives of the bidders interviewed by the committee had several reservations.

The committee appointed by the GoS found that the consultants did not see the current climate as being favourable for a smooth transaction ${ }^{7}$. The committee was doubtful about the sustained working of foreign investors in a politically uncertain climate such as Karachi. The committee was also averse to putting an excessive burden on low-income groups should there be tariff revisions. In addition, there was no clear strategy in the PSP regarding squatter settlements, where about half the urban population resides. In sum, the independent committee found that the upper management of the GoS/KWSB were only interested in putting in motion the process of eliminating the debt that the KWSB had accumulated since its creation in 1983. However, even

\footnotetext{
${ }^{7}$ Communicated through a letter to the Managing Director of KWSB, dated 4 June 1998.
} 
on these grounds, no sizeable evidence was found that the strategy would succeed, as the successful bidder was to be given a five-year concession ${ }^{8}$ (Usmani et al., 1999).

\subsection{The KWSB's response}

The staff, union, engineers and officers of the KWSB board also gave their views on the issue of privatisation. All the cadres of KWSB staff were against PSP, though for a variety of reasons. In their view, the PSP process evolved as a result of World Bank advice, not because of local demand. No options of any PSP were discussed by the KWSB neither in their board meetings nor at any other forum before it was promoted by the Bank. Besides, since no scientific study was ever conducted to ascertain the demand, it could only be inferred as a donor driven strategy. Also, essential stakeholders—-that is, consumers, KWSB staff and the governmentwere unable to participate equally in the process, while the PSP was finalised in secrecy without even bringing in the governing body of the board. The KWSB staff members were also of the view that other possible options were not explored. For example, innovative strategies of cost recovery, along with suitable legislative and administrative cover, should be worked out as an initial measure towards improvement. The apparent problems of the water supply and sanitation were probably known to all, but they required objective study to identify the root causes and help develop a possible solution. In this case, it appeared that a prescriptive approach was adopted. Since the Bank was already involved in enforcing privatisation in other contexts and sectors, it probably applied the same logic to KWSB. Besides, the whole process needed to be carried out openly to curb chances of malpractice and to ensure transparency.

\subsection{Water traders}

\footnotetext{
${ }^{8}$ According to various financial documents on the issue, the outstanding loan of KWSB was as high as US\$1 billion, almost 20 times the total annual budget of the KWSB.
} 
Owing to the inadequate and improper piped system of water supply, many informal modes of water vending have emerged in Karachi over the years. Though informal, these modes are highly organised and possess a well-defined clientele for their operations. Water vending takes place through water tankers, donkey carts, pushcarts, manual water carriers and community water taps in squatter settlements. In this category, two representatives were approached—a former chairman of the Karachi Water Tanker Association and a tanker operator.

According to their views, at least $10 \%$ of the urban population of Karachi depend directly upon tankers. Because of this poor level of service, the KWSB may not be able to recover its bills. In the view of the water vendors' representatives, privatisation is not likely to solve these problems. They believe the government should invite all the stakeholders to discuss the issues relating to privatisation.

The water traders also believe the poor have already been purchasing water at high prices. Thus, if the service level improves as a result of privatisation, it may not be a bad choice. However, water vending practices will continue despite privatisation. Vending will continue to serve the population that is denied access to piped water at the moment. The KWSB feeds a limited area and clientele and a sizeable number of consumers are likely to remain dependent on the tanker service, particularly in low-income areas.

\subsection{Real estate builders and developers}

The wide-ranging residential construction undertaken by real estate builders and developers makes them a major stakeholder in the water sector. Builders and developers were approached through their union, the Association of Builders and Developers (ABAD).

In ABAD's view, the KWSB's performance was below the desired level. A serious gap prevailed between supply and demand, water leakages were on the rise, thefts had increased and 


\section{N. Ahmed and M. Sohail / Water Policy 6 (2003) 229-247}

the board was failing to recover revenue and to monitor the revenue it did recover. These were the main reasons that had led to the privatisation. ABAD believe the KWSB has the potential to rectify its defects, but think that it does not have the will to do so. The objective of privatisation should be to raise the performance of the institution while keeping the service affordable to the average citizen.

ABAD expect the water supply system to improve after privatisation. They also think the private sector is likely to detect a smooth and periodical recovery of revenue across the means of water supplied. The administrative and managerial performance of the KWSB is also likely to improve after privatisation. Technical standards would improve and staffing would be rationalised. More funds could be made available for development and extension of the network.

However, these improvements will largely depend upon the process, procedure and system of privatisation adopted. If privatisation were carried out in a similar manner to that in common enterprises such as banks, the results would be disastrous. The builders and developers believe that, owing to its very different nature, the water utility’s privatisation needs to be carefully worked out. The current process of privatisation is not appropriate. The KWSB is being directly sold to a foreign company. Another concern of the builders and developers was that tariffs would rise monumentally. This would be a burden on the people, especially low-income groups.

ABAD think that the best way could be to privatise gradually so that minimum disturbance occurs and the whole process is completed in a smooth and transitional fashion. In the public interest, there should be a local partner firm that could work with the foreign firm for a stipulated period. Then the local firm could eventually take over after developing adequate capacity. 
A basic prerequisite of privatisation could be to search and develop alternate sources of water, such as desalination. There is a possibility that the water quality would improve after privatisation. However, the sewerage sector services would require proper investment and planning in accordance with the enhanced water supply. Privatisation may help remove the serious ills of KWSB, such as overstaffing. However the prerequisite for privatisation should be to ensure supply that is proportional to needs. Squatter dwellers also need to be brought into the tax net.

\subsection{Local politicians}

Karachi was governed by an elected municipal government for a very short period of time during its post independence history. The Karachi Metropolitan Corporation, now defunct, was replaced by a City District Government that was run by an elected mayor and councillors for a little over 10 years. A twice Mayor of Karachi, who was also the Chairman of the KWSB (by virtue of his mayoral role), was interviewed. In addition, a local councillor was also interviewed who has been active in local politics for a very long time. He belongs to a small, low-income settlement in Karachi.

In the view of the former mayor and the councillor, the people, including consumers, staff and politicians, are generally against privatisation. For them, the most significant impact of privatisation can be unemployment. The local politicians believe that the KWSB (and other similar institutions) are being forced into privatisation because of the financial malpractices of politicians. Resource scarcity is a prime reason for the leakages and thefts, which remain unchecked in the water and sanitation sector. They held the view that a prerequisite for financial improvement of the KWSB is to have honest people in all the departments. Legally, all the properties and assets of the KWSB belong to the city municipality. Therefore, the municipality 
must also be consulted. They also think tariff increases and price hikes will be devastating, especially for poor people.

Generally, privatisation has not proved successful in many units and enterprises that have been privatised. The objective of privatisation should be to provide the best possible service at an affordable price. These local politicians think the privatisation of the KWSB will have grave social implications for the people, including unemployment of staff. An alternate path would be to increase the salary scale of workers to prevent them from entering into corruption. Besides, the workers should be consulted before any move is finalised.

\subsection{Consultants}

Three consultants who have direct experience of privatisation were interviewed. Their views are summarised below.

The consultants thought, as a result of privatisation, people will have to pay extra charges for the same kind of service that is available to them today. Privatisation is likely to be unjust for Karachi. Poor people, in particular, will not be able to obtain water after the system has been privatised and only affluent areas may benefit. This is because the private operator will provide water only to those who can pay for it. Neither quality nor quantity of water is supposed to improve after the PSP. In addition, any improvement in administrative affairs will only arise if it is desired by the private operator. In general, the consultants think that the present method of privatisation is not desirable in the current scenario.

The consultants believe that for privatisation to be successful it is important that monopolisation of the system be avoided. During privatisation the focus should be on improving services and letting technical people take over affairs without interference from politicians. In addition, decision making should be done transparently, without any trace of malpractice or 


\section{N. Ahmed and M. Sohail / Water Policy 6 (2003) 229-247}

underhand dealing. The government must also develop a physical plan to execute decisions such as privatisation. The demand for and supply of water also needs to be reassessed. The consultants think that consumption, not the characteristics of location, should be made the basis of water charges. In addition, if need-based planning is not carried out for water supply, then there are likely to be water riots. By relying on the honest and capable human resources of the KWSB, and by recruiting more such people, KWSB affairs could be structured properly.

\subsection{City administrators}

During the entire post-independence period, the administration of water supply was controlled by three institutions. These were the Karachi Metropolitan Corporation, the Karachi Development Authority and, lately, the Karachi Water and Sewerage Board. The earlier two are now defunct having been merged into the City District Government of Karachi (CDGK) in 2001. The former heads of these three institutions were interviewed. Their views are given below.

In the administrators' view, privatisation may not be useful as it will be difficult to get a sincere buyer for the whole exercise. Before resorting to privatisation, they said, other alternatives should be carefully studied, making increases in the source of water the top priority. They believe a private entrepreneur would find it even more difficult to recover revenue and would be unable to solve problems such as faulty billing, recovery and operational systems. Different internal systems within the KWSB need to be considered and this should be done without delay.

The administrators think it is only the World Bank that is pushing for privatisation. Other donors are not informed or properly involved in the process. In addition, the procedure that has been adopted for privatisation is faulty and full of loopholes. It will give rise to confusion and bad performance. Qualified and trained staff are also in short supply in the KWSB, while the 


\section{N. Ahmed and M. Sohail / Water Policy 6 (2003) 229-247}

problem of political appointees is giving rise to issues such as alleged overstaffing. Nor have innovative solutions been included in the privatisation procedure, for example, desalination. Finally, the administrators said that privatisation of the water supply was not advisable from the defence and internal security point of view. It may render the city vulnerable to external threats.

\subsection{Concerned citizens’ groups}

There were several citizens' groups who showed deep concern about the adopted process of PSP. Three such groups were interviewed, each having divergent views. These interviews were held between February and April 1999. These are summarised below.

One group thinks that privatisation may be a good option. The present system has been disappointing for those who pay their bills but do not get water. Low-income localities, on the other hand, often steal water, creating a burden on paying citizens. As the KWSB continues to remain politically motivated, mismanaged and corrupt, privatisation appears to be the last resort. This first group believes that protection should be sought for the paying citizens.

In the view of another citizens', if core government departments settle their water bills ${ }^{9}$, then perhaps privatisation may not be needed. For them, privatisation is not advisable. It may give rise to price hikes, unemployment and cause an end to public control. Without an appropriate dialogue to streamline the objectives of privatisation, decentralisation and to involve people, this kind of experiment will not succeed. This second group also believes that privatisation of the KWSB may not improve levels of service. People are likely to pay a higher price for an inferior service. Nor will the system improve as a result of privatisation; people will continue to get bad quality water. This group also found it difficult to believe that a foreign

\footnotetext{
${ }^{9}$ Water bills of several core government departments are lying unpaid. Because of their administrative clout, they succeed in delaying the payment, causing hardship to the water utility.
} 


\section{N. Ahmed and M. Sohail / Water Policy 6 (2003) 229-247}

investor would come and invest in a sector in which the government itself is not investing ${ }^{10}$ ! In addition, the situation of sewerage can become worse as it may not receive attention and investment. Privatisation will cause burden on common people.

The third citizens' group thought that, in order to improve the water supply and sanitation service and to make people pay user charges, the KWSB should be privatised. The objective of this privatisation should be to improve efficiency and service delivery. If appropriate research is carried out and the privatisation is based on the findings of this research, then privatisation is likely to give positive results. This group also believed that privatisation can improve the water supply and sanitation service. For them, a regulatory system is needed to ensure proper water quality, accountability and transparency of operations. Standard rules, regulations and procedures of privatisation should be followed during the process. Also, the government should reduce its role and promote good governance. While privatisation is not a bad option, it may not be properly carried out in the KWSB's case because of the culture of developing monopolies and bypassing rules and regulations. The objective of privatisation, in general, should be to provide the people with basic services (water included) at affordable prices.

Others thought that, owing to rampant thefts and leakages, precedents of corruption and overstaffing, the privatisation might not be a successful event. However, privatisation could be useful in a limited way_-for example, it can motivate employees to work. In addition, administratively, the KWSB may improve after privatisation. By improving water management and by controlling the thefts/leakages, the water supply and sanitation system could be largely improved. There is also a possibility that the KWSB could gain financially and administratively.

\footnotetext{
${ }^{10}$ This viewpoint evolved from the fact that the routine maintenance and upkeep of water-related infrastructure was grossly dismal. The government departments responsible for them were not investing even sufficient capital to maintain these service delivery assets. It was therefore difficult for common people to understand the reasons why a foreign investor would put capital into a sector that was found practically unworthy of governmental attention.
} 


\section{N. Ahmed and M. Sohail / Water Policy 6 (2003) 229-247}

However, in their opinion, water quality may not improve after privatisation. The privatisation may also cause unemployment, while water and sanitation services may become expensive and unaffordable. For this group, the prerequisites of privatisation include eradication of corruption, affordable delivery of water (at least for basic needs) and a mechanism of just distribution. People should also be consulted during the privatisation process. In their view, the union of the KWSB is opposing privatisation for its own interests; the greater interests of consumers should be upheld in all the moves.

\subsection{Residents of planned areas}

Mostly, the residents of planned areas have regular water connections and receive water/conservancy bills. However, different areas have different levels of service. The water supply and sanitation situation is bad in many new areas as well as in the old town. The residents of an apartment complex in a planned locality were interviewed.

These residents say they have no idea about what the benefits will be from privatisation because this aspect was never made public. However, they see that their water bills are rising monumentally. They paid Rs569 per year per house in 1996. Now the average bill is Rs3600, despite the fact that the service has declined. In addition, they have to pay for tankers during the peak of summer. The residents interviewed say they cannot pay inflated water bills any longer. In their view, whoever takes over the KWSB should try to manage it on the same budget. Although they say that if they can get a continuous supply of clean, pure drinking water they may think of paying more, they believe that this is not possible. The apartment complex residents doubt that privatisation will do any good to the existing system.

2.10. Residents of unplanned areas 


\section{N. Ahmed and M. Sohail / Water Policy 6 (2003) 229-247}

There are 568 squatter settlements in Karachi, where more than half of the city's population live. These squatter settlements, which are of different ages, size, socio-economic composition and location characteristics, also have different levels of basic services available to them. Some of these settlements are very old, even older than Pakistan. Others are new and have only developed recently. In order to obtain feedback from the residents of unplanned areas, two forums were held ${ }^{11}$. One forum was held in a service sector settlement located at the edge of an affluent area of the city. The second was held in a traditional squatter settlement along an old river bed location. The results of these interviews are summarised below.

The first forum found that, in terms of improvement of services, privatisation of the KWSB might be useful. However, all the details relating to the privatisation must be made public before any decision is taken. Privatisation will force the people of squatter settlements to safeguard their internal infrastructure so as to avoid losses and thefts. Although privatisation of the KWSB can be beneficial for the government, the benefits to the citizens are not so clear. In the view of this forum, the staff of the KWSB should be protected during the privatisation, while at the same time being given more powers to perform their duties effectively. They believe the KWSB and the private company should form a partnership ${ }^{12}$. They should develop standard rules for the provision of water and sanitation services. The people on this forum thought that if the KWSB stays as a government institution, if will be favourable for the poor.

The second forum said that people in low-income settlements do not get water despite their paying water bills. In their view, if privatisation has to take place, the tariffs should be kept compatible with the average person's paying capacity. In observing experiments in the past, it

\footnotetext{
11 These forums were organised and conducted by the authors during the course of this study. Ordinary residents from two large squatter settlements were requested to participate. The squatters were located in the west and south of the city. They were chosen randomly, however, considering the fact that they were more then two decades old.

${ }^{12}$ In a very modest way, the community leader was referring to the concept of public-private partnership.
} 


\section{N. Ahmed and M. Sohail / Water Policy 6 (2003) 229-247}

appears that privatisation will give the successful bidder monopoly powers. Also, the government will not be able to safeguard people's interests. Hence, in these people's view, the outcome of privatisation may lead to an increase in user charges. However, this can be prevented by increasing connections and improving facilities. For them, there are two aspects of privatisation: one, people would get clean and adequate water and two, prices would rise considerably. If this happens, then the government must ensure price control. The second forum thought that certain problems within the current system would be eradicated as a result of privatisation. Financial bungling in the award of contracts, corruption, wastage of water and political interference could be controlled. They thought people's representatives should be assigned the task of monitoring the performance of private company ${ }^{13}$.

\section{Analysis}

The KWSB has serious weaknesses in its operational, managerial and financial systems. As is apparent from the stakeholders' responses above, political interference, thefts and leakages, a poor system of revenue recovery and dubious methods of awarding contracts are some of the common problems.

With regard to the privatisation, decision making and follow-up implementation were not done in an appropriate and consistent manner, which resulted in several setbacks. The initial strategy was worked out in a clandestine manner without consulting the KWSB staff. Thereafter, decisions were announced in a hasty manner, which created mistrust among the stakeholders. The matter was not even brought to the KWSB board/governing body for review, comment or routine discussion ${ }^{14}$. In sum, the private sector participation approach was perceived as a

\footnotetext{
${ }^{13}$ It was a very useful idea, which was also reported in some press statements during these deliberations. However no response was given by the authorities about the feasibility (or otherwise) of its implementation.

${ }^{14}$ Interview with Mr. Abdul Baqi Siddiqui, former Managing Director, KWSB, Karachi.
} 
clandestine plan of the upper tiers of government that was implemented from the top rather than evolving from the ground upwards.

During the next stage, the process of launching the PSP, the short-listed contracting firms were all foreign. No local firm was invited to join the bidding process or to enter into negotiations. There are several reasons associated with this. First, local engineering firms do not have any previous experience of running a water supply and sewerage service. Therefore, only those firms who had a track record of managing this kind of service were invited to participate. Second, the short-listed firms’ systems of working were compatible with the organisational culture and approach of the donor agencies (principally the World Bank) ${ }^{15}$. Hence, the donors preferred to involve only these firms in the process. Third, it was advisable to involve foreign firms so as to avoid any local political interference in the bidding process. And fourth, the secrecy of the privatisation plan, which was crucial during the early stages, could only be guaranteed by involving foreign firms.

While the private sector participation strategy for the KWSB ostensibly aimed to launch sustainable reforms in the sector, the actual concept adopted for the process is different. The government officials concerned, in association with the World Bank, devised a strategy practically to sell the KWSB to a private operator. In this they would have provided various concessions, subsidies and risk management guarantees. It was not a balanced procedure since it safeguarded the interest of only one actor, the private operator. The interests of the government and consumers were not guaranteed.

In addition, the theme of the chosen strategy did not focus upon the root cause of nonrecovery of user charges, which was due to the poor level of service provided by the KWSB.

\footnotetext{
${ }^{15}$ The consultants had very clearly recommended the international water companies for PSP owing to their past experience.
} 
Rather, the strategy only emphasised steps to recover user charges and dues. Consumers held the view that they were willing to pay their charges promptly provided they obtained proper services in return.

The details of the procedures were not scientifically developed. Before formulation of the PSP strategy there was no survey of the existing network of supply and pumping, nor was any system documentation carried out. Similarly, various contextual realities were not outlined in the process. For example, the KWSB has been the subject of political interference throughout its existence. No mention was made of how this political interference, both internal and external, could be countered. Therefore, many ambiguities would have been left inbuilt into the privatisation process.

It is also clear from the above interviews that the viewpoints, interests and objectives of the various stakeholders were not included in the system of privatisation, nor was anyone invited to voice their opinions. Although the proposed PSP strategy suggested the creation of various organs, such as a water commission, the adopted strategy did not include peoples' points of view at any stage $\mathrm{e}^{16}$. The water supply and sanitation service has a large number of stakeholder groups. They comprise consumers/users, professionals, the staff of the KWSB, water vendors, local politicians, area leaders, city administrators, businessmen and other groups. These groups were largely ignorant of the formulation of the PSP strategy for the KWSB ${ }^{17}$.

The feasibility report that was prepared by the consultants does not register the prevailing trends and user responses to the water and sanitation services. While the report does mention the fact that consumers are dissatisfied and thus not willing to pay, it does not suggest ways by which consumers could be motivated to pay their water bills. The entire weight of the feasibility

\footnotetext{
${ }^{16}$ As is clear from the earlier description, the first visible form of consultation on a limited scale was only done by the Independent Committee. The GoS did not consult the people directly about PSP at any stage.

${ }^{17}$ For details see Ercelawan and Nauman (1998).
} 


\section{N. Ahmed and M. Sohail / Water Policy 6 (2003) 229-247}

report rests on factors that are not consumer driven. For example, the feasibility of the PSP strategy recommends the enhancement of foreign investment in the water and sanitation sector, reducing and finally eliminating government subsidies and relying on the partial risk guarantee (PRG) committed by the World Bank. The Steering Committee on the PSP approved these recommendations despite the fact that the independent committee rejected this approach on the grounds that the World Bank itself had said that the PSP might not be an advisable option in the current circumstances.

The consultants' report, along with feedback from the stakeholders, clearly reveal that the private operator would rely and work with the existing source and network arrangements without any major system improvements. Thus, the quantity of water and the type of sewerage disposal available to the city would remain the same after privatisation. It is also assumed that since the private operator would not be in a position quantitatively to add water supplies, it would have to resort to the same cycle of water provision and allocation. As a result, people would not experience any visible change after privatisation, at least during the first few years. Besides, as the population is growing and new apartment/residential/commercial projects are emerging, pressure will mount on the private operator to sanction new connections, thus exerting a greater load on the existing supply.

From the above, it is clear that people would be paying more for the same (and perhaps worse) system of water supply and sewerage service after privatisation, if the adopted strategy for PSP were to go ahead. As a result, there would be widespread resentment. Many people believe privatisation to be synonymous with a drastic improvement of services, yet in the current situation in Karachi it would mean a stagnation of service standards. It is also a common 
observation that the private operator would refrain from undertaking of any major capital expenditure, at least during the initial period after privatisation.

It should also be noted that privatisation of water and sewerage service will have a direct effect on the existing set of stakeholders involved in the water trade, most of whom are completely ignorant of its process and dynamics. Since their economic, social and political interests will be affected, they will be likely to resist the operations of the private operator. This may have an adverse effect on the performance of the private operator ${ }^{18}$.

Finally, the economic and financial analysis conducted by the consultants was based on data supplied by the KWSB and other government departments. The realities of the situation are different from these facts and figures and other information used. This will lead to underestimates as far as the demand and consumption aspects of planning are concerned, while overestimates on the supply side will also result.

\section{Conclusions}

It is apparent that there are two clear views of private sector participation in the KWSB. The policymakers justify the privatisation of the KWSB on the grounds of financial malpractice. As a result, they have devised solutions that primarily focus upon the financial reincarnation of the KWSB. Stakeholders, on the other hand, are critical of the KWSB's service delivery process and view privatisation as a possible tool to remedy the system. However, the private sector participation strategy that has been prepared by the decision makers concerned only remedies the financial aspects and does not guarantee service improvement.

\footnotetext{
${ }^{18}$ This is exactly what happened in the privatisation of solid waste management services in North Karachi and the Federal B Area of Karachi Central District. The sanitation workers and their political patrons employed various illegal means to hamper the work of the contractor in order to retain their jobs and pressurise the District Municipal Corporation.
} 
In the prevailing political and administrative climate of Sindh, the privatisation of the KWSB using the present strategy will be difficult. Even the World Bank has shown its reservation (according to Usmani et al., 1999). However, at any later stage the government is likely to revise the process and reapply it in a mode that conforms to the objectives of the donor agencies.

Absence of commitment from the different ranks of management in the KWSB will also pose a serious problem in the application of any PSP strategy. While the upper tiers of government are powerful, the staff and management of the KWSB have the capacity to create resistance. The court cases filed by the labour union of the KWSB and its former managing director are examples.

The dynamics that led to the creation and application of the PSP clearly suggest that it has been imposed from the top as a macro-level decision, without the decision makers gauging fundamental, ground level realities. Background analysis of the PSP shows that there was no informed decision making. No study or serious dialogue was conducted and this eventually led to procedural problems. If privatisation is implemented, the worst off will be the low-income groups who have least financial and procedural choices.

While the KWSB has been declared financially impotent, the reasons behind this have been neither documented nor analysed during the decision-making process. Only the end state of the KWSB has been used as a strong reason for its nascent selling in the market.

In addition, the various linkages that operate in the water supply and sanitation sector have not been taken into account. Thus, decision making has entirely relied upon the general information that is available or that has been provided by official sources. In this way, the fact 


\section{N. Ahmed and M. Sohail / Water Policy 6 (2003) 229-247}

that water is already traded as a saleable commodity, one that has a widespread market of buyers and sellers from upper- to lower-income groups, has been missed.

From the proposed privatisation strategy there appears no convincing evidence about how the system would improve after privatisation since the proposed private operator has been advised to focus only on tariff enforcement and improving revenue collection. The entire feasibility study submitted by the consultants can be cited as an illustration of this.

The compound after effects of the privatisation of the water supply, given the proposed tariff rates, will be very severe. However, this has not been accounted for or analysed. When there is a rise in water prices, all the goods and services that use water in any way will experience a rise in price. The poor will be directly affected as a result.

People are aware of the overall performance of the KWSB and of the crises in the water and sanitation sector. In principle, they are not against privatisation. However, consumers demand a reasonable service on a proportional tariff structure that is compatible with their socioeconomic status.

\section{Recommendations}

In response to the above analysis and conclusions, the following recommendations should be considered. They are cited at three levels: conceptual, structural and financial.

Conceptually, the objectives of privatisation need to be revised. It is apparent that the financial aspect is the key factor around which the PSP strategy was devised. A more appropriate priority would be to devise a strategy for optimum service delivery to people at an affordable and acceptable charge. Involvement of stakeholders is vital to seek their cooperation, develop consensus and minimise resistance. The CDGK being the representative local government at present may initiate the process. 
Water has been a public good throughout Karachi’s history. If water is transformed from a public good to a private one, and its supply is transferred from public service to a commercial outlet, then privatisation may not succeed. Therefore, in the real terms, an approach needs to be devised whereby water as a public good can be supplied to people through appropriate participation by the private sector. This may include the involvement of various service providers on a contractual basis working under the control of a public body. Billing and recoveries, retail distribution, repair and maintenance, emergency/relief supplies through tankers and addressing operational complaints are a few areas where the contracted input of private sector may be attempted.

Structurally, the KWSB’s services may be disaggregated. If any alternative strategy has to be recommended, it should be based on the concept of unbundling the water and sewerage services. The production of potable water in bulk, the distribution network of water throughout the metropolitan city area, water distribution in bulk for identified and organised areas, sewerage collection, transmission and treatment etc. could be handed over (after decentralisation) to the organisations listed below.

- $\quad$ The City District Government of Karachi (CDGK) for the production of raw water and its treatment;

- $\quad$ The KWSB (now WSD) for the distribution and conveyance of water to various points in the city;

- $\quad$ The town municipal administrations for the retail distribution of water and management of sewerage and sewage collection;

- $\quad$ The private sector - any of these unbundled units could be contracted out to the private sector through a carefully considered arrangement; 
- $\quad$ A regulatory body—could ensure the smooth functioning of all the organisations, undertaking necessary but minimum coordination between them, keeping a watch on the performance and achievement of negotiated targets and looking after the interests of all consumers in an equitable manner. If this concept is accepted by the GoS, details will have to be worked out by consultants in association with professionals, NGOs/CBOs and other relevant $\operatorname{organisations}^{19}$.

As proposed by various stakeholders, and also apparent from the balance sheet of the KWSB, a concentrated effort must be made to recover the maximum amount in water charges based on the existing billing structure. However, the recovery drive must proceed in line with visible improvements in services. Various options for bill recovery should be studied. For example, the water bill can be tied up with land revenue. Another option is to attach/include water charges with electricity, gas and telephone charges. This would create easy access to a maximum number of consumers. It is apparent that if the KWSB recovers up to $80 \%$ of its bills, it may resolve the collection problems without involving operational control of private firms.

\section{Acknowledgement}

This paper is based on a study that was supported by WEDC, Loughborough University, UK. The views expressed here should not be attributed to WEDC, Loughborough University, UK or NED University, Karachi, Pakistan.

\section{References}

Ahmed, N. (1998). Privatisation of Water Supply and Sanitation in Karach. Draft Final Report prepared for WEDC, UK.

\footnotetext{
${ }^{19}$ This suggestion was formulated by the Independent Committee on PSP.
} 
N. Ahmed and M. Sohail / Water Policy 6 (2003) 229-247

Briscoe J. (1997). Managing Water as an Economic Good: Rules for Reformers. Keynote Paper, the International Committee on Irrigation and Drainage Conference on Water as our Economic Good. Oxford, UK.

Banque Paribas (1997). Private Sector Participation in KWSB: Strategy Report. KWSB: Karachi, Pakistan.

Cheghtai, T. (1998). Tanker mafia_earning rs.2.5 million daily. Jafakash Monthly (in Urdu). Karachi, Pakistan.

Ercelawan, A and Nauman, M (1998). Reforming Urban Water Services in Pakistan. Paper presented at 24th Water Engineering and Development Centre (WEDC), Loughborough University Conference, Islamabad.

KWSB (1998). Karachi Water and Sewerage Board: Basic Facts-1998. KWSB: Karachi, Pakistan.

Rivera, D. (1996). Private Sector Participation in the Water Supply and Waste Water Sector. The World Bank: Washington DC.

Usmani, M. R., Pasha, A. G. \& Zaman, A. (1999). Report of the Committee on Privatisation. Final report submitted to the Government of Sindh. Karachi, Pakistan.

UNCRD (1998). Metropolitan Governance and Planning in Transition: Asia-Pacific Cases. United Nations Centre for Regional Development: Nagoya.

WSP (1998). A Glance at Water Vending in Karachi. Field Note, Water and Sanitation Programme: Islamabad, Pakistan.

Whittington, D. (2003). Municipal water pricing and tariff design: a reform agenda for south asia, Water Policy, 5, 61-76. 
N. Ahmed and M. Sohail / Water Policy 6 (2003) 229-247

Table 1. Water supply and sanitation in Karachi-some basic facts.

Bulk water supply 388 million gallons

per day (mgd)

Bulk water demand 665 mgd

(1997)

Bulk water supply $\quad 605$ mgd

(2000) (projected)

Bulk water demand $\quad 820$ mgd

(2000) (projected)

Water demand (1998)

Low-income localities 63 litre/capita/day

Middle-income 132 litre/capita/day

localities

High-income 335.5 litre/capita/day

localities

\section{Bulk water supply}

\section{Quantity (water)}

1. Indus

2. Haleji

3. Dumlottee

\section{INVENTORY OF SERVICES}

\section{$\underline{\text { Retail water supply }}$}

1. Water mains and 3360 miles

distribution lines

263 mgd

2. Pumping station

and boosting

3. Community taps 3378

4. Hydrants (for

10 
tanker supply)
4. $\mathrm{Hub}^{\mathrm{a}}$
100 mgd
5. Water tankers
28 Nos
Total
388 mgd
6. Reservoirs
8 Nos

\section{Sources}

1. Dumlottee wells 7 Nos

Sewerage services

2. Dumlottee conduit 25 miles

1. Trunk sewers

113 miles

2. Sub mains and

2700 miles

lateral sewers

3. Haleji conduit

60 miles

3. Rising mains

44 miles

4. Indus system

80 miles

4. Treatment plant ${ }^{\mathrm{b}}$

2 Nos

(20 mgd each)

$\begin{array}{llll}\text { 5. Hub system } & 35 \text { miles } & \text { 5. Pumping station } & 24 \text { Nos } \\ \text { 6. Major pumping } & 10 \mathrm{Nos} & \text { 6. Automatic sewer } & 12 \text { Nos }\end{array}$

station

cleaning machine

7. Filter plants

7. Main/sub mains

272 miles

sewer

$\begin{array}{lll}\text { Gharo } & 2 \text { Nos } & \text { 8. Ejector } \\ \text { COD Hill } & 2 \text { Nos } & \end{array}$

Pipri and Gharo $\quad 2$ Nos

North East Karachi 1 Nos

8. Tunnel 21/2 miles

a. Hub source is fast drying up.

b. A third treatment plant is being built at Mauripur, Karachi West.

Source: KWSB, 1998. 
N. Ahmed and M. Sohail / Water Policy 6 (2003) 229-247

Table 2. KWSB—evolution of private sector participation (PSP).

\section{KWSB privatisation}

- $\quad$ Preparation and implementation of private sector participation in the Karachi water supply and sewerage sector.

\section{Project objective}

- $\quad$ To assist the Government of Sindh in preparing and implementing a transaction that will efficiently involve the private sector in the provision of Karachi's water supply and sewerage services.

\section{Three-phase approach}

- $\quad$ Phase I covers the development of the most appropriate PSP strategy.

- $\quad$ Phase II covers the preparatory work for private sector participation.

- $\quad$ Phase III covers the implementation of the recommended and agreed programme.

\section{Phase I: Strategy development}

- $\quad$ Recommend a preferred approach for private sector participation (PSP).

- $\quad$ Explore the potential and benefits of horizontal unbundling of the integrated water supply and sewerage system.

- $\quad$ Define the broad legal and regulatory framework and the role and responsibility of the government.

- $\quad$ Seek agreement from the relevant government agencies on the preferred PSP design.

Deliverable aims for Phase I

- $\quad$ A report on the design of the preferred approach for the Karachi water supply and 
sewerage sector

- $\quad$ Agreement from the GoS, the Privatisation Commission and the Ministry of Environment and Urban Affairs on the recommended approach

\section{Phase II: Preparation}

- $\quad$ Evaluate, in detail, the risks involved in the chosen PSP approach.

- $\quad$ Evaluate the technical and financial feasibility of the chosen PSP approach.

- $\quad$ Review the investment needs and objectives and propose an overall strategy for project finance.

\section{Deliverable aims for Phase II}

- A detailed technical and financial feasibility report

- $\quad$ Detailed assessment of the impact of introducing the recommended PSP approach

- $\quad$ A project finance strategy and plan for mobilising the investment needed

\section{Phase III: Implementation}

- $\quad$ Preparation of documents:

- $\quad$ prepare a brief but effective prequalification document;

- $\quad$ prepare all bidding documents.

\section{Deliverable aims for Phase III $^{\mathrm{a}}$}

- $\quad$ Prequalification documents

- $\quad$ Bidding documents

a. Could not be undertaken as the process was halted in 1996 by a court order. Source: KWSB, 1998.

Table 3. Summary of stakeholders’ response. 
N. Ahmed and M. Sohail / Water Policy 6 (2003) 229-247

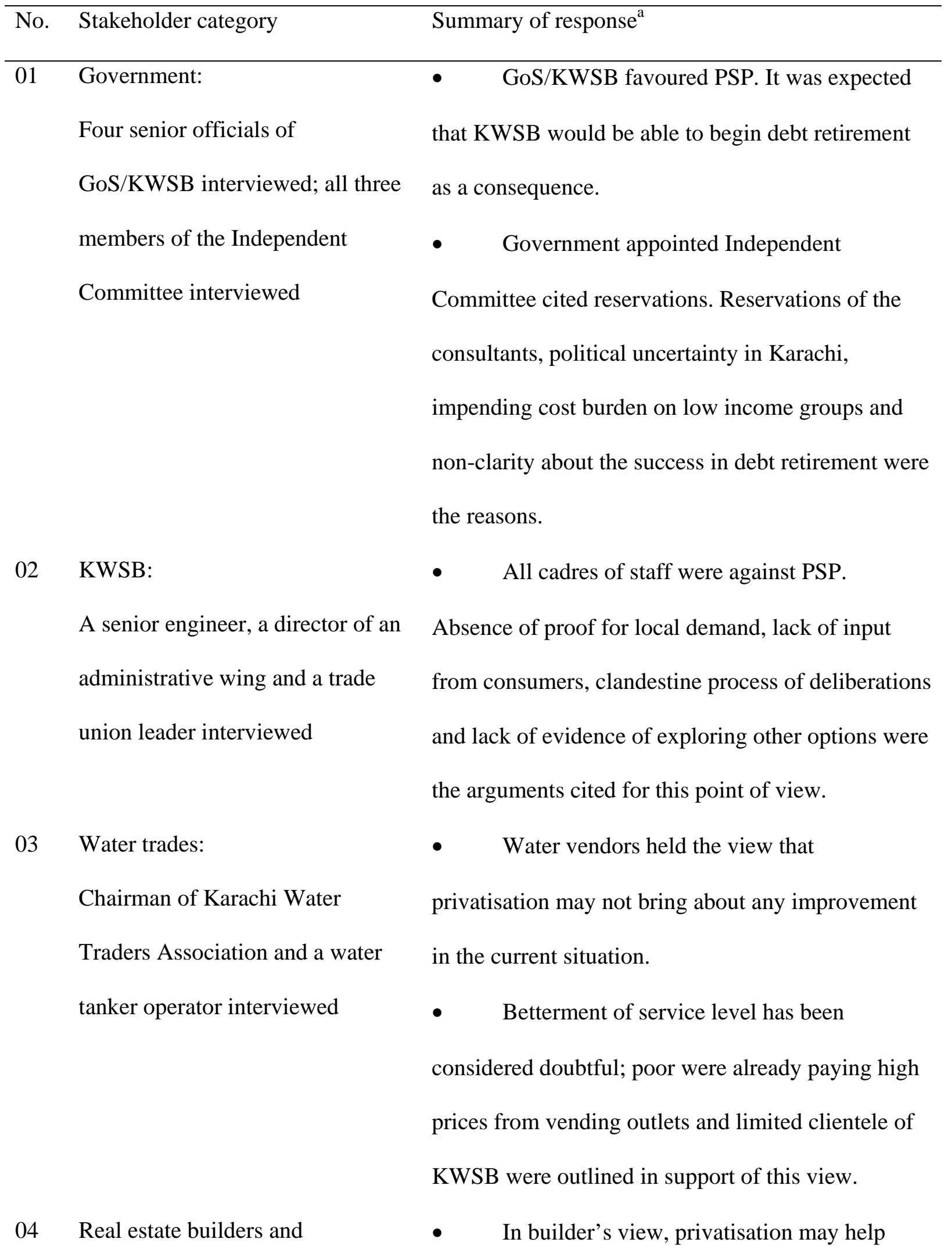


developers:

Chairman, Association of Builders

and Developers, a former

Chairman ABAD and a local

builder interviewed

05 Local politicians:

A former mayor and municipal

councillor interviewed

06 Consultants:

Chief Engineer of a large local consulting firm, an independent consultant and a former

Chairperson of Institute of City and Regional Planning interviewed

07 City administrators:

A former Director General, Karachi Development Authority improve the situation.

- If technical standards are improved, staffing rationalised and minimum disturbance approach is adopted, it may be successful.

- $\quad$ Current process was not found appropriate as the KWSB was being directly sold to a foreign company and tariff burden was likely to increase for the poor.

- $\quad$ Former major and councillor were against privatisation.

- $\quad$ Tariff hikes affecting poor people, lack of success stories in other sectors and possibility of unemployment owing to possible retrenching in KWSB were the main reasons for this point of view. - $\quad$ Consultants believed that privatisation is not required in the prevailing circumstances.

- $\quad$ Remote possibility of rise in service levels, extra price ranges for the same kind of service and possible benefits only for the affluent were the given reasons.

- $\quad$ Privatisation may not be useful.

- $\quad$ Lack of possibility to access a sincere buyer, 
N. Ahmed and M. Sohail / Water Policy 6 (2003) 229-247

and a former Managing Director

KWSB interviewed

08 Concerned citizen groups:

Convenor of a major consumer

rights group, chairperson of a

labour relations organisation,

board member of an advocacy

group, a coordinator of a

development related NGO and a

civic affairs reporter of a national

daily interviewed defence and internal security considerations, absence of innovative components and incomplete participation of associated donor agencies are the reasons.

- $\quad$ One group felt that privatisation might be a good option for paying consumers. It might improve the service delivery.

- $\quad$ A second group felt privatisation is not advisable as it will not improve service. Perhaps if defaulter departments pay water bills, privatisation may not be needed at all.

- $\quad$ Third group believed that KWSB should only be privatised if service levels are expected to improve. Eradication of corruption, affordable delivery of water and due consultation with people were the key factors cited as pre-requisites.

- $\quad$ They knew little about privatisation.

Thirty five residents of apartments and single unit housing participated in a focused group meeting

10 Residents of unplanned areas:

- $\quad$ One group felt privatisation may be useful Two focused group meetings held but its benefits are neither clear nor made public. 
N. Ahmed and M. Sohail / Water Policy 6 (2003) 229-247

in two separate squatter

settlements with a total

participation of around 40
- $\quad$ Second group favoured privatisation conditionally if the level of service rises and water supply becomes affordable.

residents

a. All the interviews were based on a structured questionnaire. Focused group meetings were conducted on the basis of a checklist agenda, although a great deal of free discussion was allowed and encouraged. 